\title{
The Design of the Automobile Brake Cooling System
}

\section{Gaohui Li}

School of Automotive Engineering, Shanghai University of Engineering Science, Shanghai, China

Email: ligaohui011@126.com

How to cite this paper: Li, G.H. (2018) The Design of the Automobile Brake Cooling System. Open Access Library Journal, 5: e4567.

https://doi.org/10.4236/oalib.1104567

Received: April 4, 2018

Accepted: April 26, 2018

Published: April 29, 2018

Copyright (C 2018 by author and Open Access Library Inc.

This work is licensed under the Creative Commons Attribution International License (CC BY 4.0).

http://creativecommons.org/licenses/by/4.0/

\section{(c) (†) Open Access}

\begin{abstract}
Because the car must be in the process of braking, including deceleration and parking and including downhill to maintain the speed of stability, in addition to the above driving brake should also include parking brake which is to maintain the stop of the vehicle that continues to maintain static, according to the law of Conservation of Energy. The kinetic energy of the brake drum of the rotating part of the friction pair is converted into the internal energy of the friction plate on the friction surface, which is very dangerous due to the thermal decay performance of the existing brakes. It is urgent to implement the cooling system of brake in the above conditions. This paper mainly aimed at the braking performance of the thermal decline of the design of automatic control cooling device, first of all by the sensor to collect the car brake signal, with the opening of the cooling system work that will be normal temperature air cooling into cold air and drum to the cooling parts, complete drum brake cooling, improve the active safety performance of automobiles. In this paper, we select the devices used in the cooling system through the actual working condition of the automobile, and finally design a practical solution.
\end{abstract}

\section{Subject Areas}

Automata, Mechanical Engineering

\section{Keywords}

Automotive Engineering, Drum Brake, Cooling System, Semiconductor

\section{Introduction}

Drum brakes, are also known as block brakes; the braking principle depends mainly on the brake shoe and brake drums close to the friction between the completions [1] [2] [3] [4]. Drum brakes have a long history dating back to the 
last century, so they were used in carriages as early as 1902, and were promoted in cars 18 years later [5] [6] [7]. The modern drum brake is the internal tensor, the braking shoe is moved outward by the function of the brake wheel cylinder, starts to rub with the inner surface of the brake drum, and the mechanical energy of the brake drum turns into the internal energy of the friction surface to complete the braking process[8].

Figure 1 is a schematic diagram of the drum brakes. Mainly includes: 1) the brake wheel cylinder, 2) brake drum, 3) return spring, brake shoe, 4) friction plate and so on. When the car is in normal running, the brake drum rotates with the wheel. The brake shoe power comes from the thrust of the brake wheel cylinder when the brake is working. As the brake shoe moves, the gap between the friction plates shrinks. The normal force of the contact surface increases gradually until the friction plate touches each other. The kinetic energy of the vehicle is converted into internal energy of the brake to achieve the braking purpose [9].

To judge the working condition of the brake, whether the braking system of the vehicle can guarantee the driving safety of the vehicle, a series of parameters is needed to evaluate it [10]. Generally, braking efficiency and vehicle direction stability are used as reference indexes. The braking principle of the above can be known in the braking process in the unit time; the brakes will produce a great brake torque, the consequences will lead to the braking process which cannot quickly emit the heat generated, and eventually lead to the thermal decay of the brakes to affect the braking efficiency and even failure [11] [12] [13].

\section{Drum Brake Thermal Decay}

\subsection{Overview of Drum Brake Thermal Decay}

Brake produces a large number of thermal energy mainly from the following centralized operating conditions [14]: 1) the vehicle driving in the long downhill to maintain speed; 2) Emergency braking. The brake load increases rapidly when

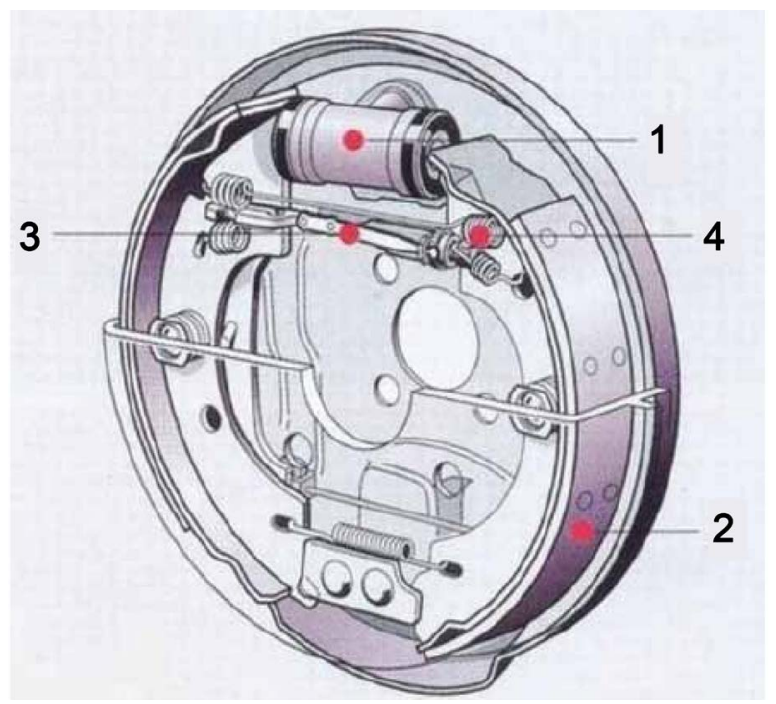

Figure 1. Wheel cylinder driving led from the hoof drum brake structure. 
the above special conditions are encountered. There will also be a large amount of internal energy, but in view of the brake itself cannot be confined to the structure of the specified period of time to disperse, resulting in the internal temperature of the brakes to reduce the friction coefficient of friction pairs, braking torque decreased, there has been a thermal decay phenomenon. The coefficient of friction is a scalar value with no dimension. It is simply a ratio of the force of friction between two objects, to the force pressing those objects together (often the normal force).

The phenomenon of declining braking performance and ablation of the brake drum is mainly caused by the continuous operation of the brake, which is reflected in:

1) When the brake is working, a large amount of internal energy can be generated within a short time, which can generate large thermal stress, reduce strength, and cause wear.

2) The brake cannot be cooled in time. The severe heat of the connecting part can cause the joint bolt to fail.

3) The temperature change of the friction material on the surface of the brake device has a great influence on the friction factor. The temperature of the friction plate is too high, the asbestos material (binder) is thermally decomposed, the friction factor is reduced, and the friction plate is easily broken during braking. As a result, the braking performance is thermally degraded.

\subsection{Brake Cooling System Status}

Among foreign heavy-duty vehicles, advanced components such as ABS (anti-lock brake systems), retarders, and automatic transmissions have long been widely used, but are rarely used on domestic heavy-duty vehicles due to cost issues. In domestic brake cooling, cooling can only be achieved by directly spraying water to the brake drum, which also shortens the service life of the brake drum.

Since 1980, research began on the cooling system of brakes. The disadvantages of traditional cooling systems include a low degree of automation and the inability to control the cooling effect. Air-cooled forced air cooling is the main method [15]. On the basis of the original brake, cooling fins are distributed on the surface. However, the cooling effect is unsatisfactory and cannot be applied to a vehicle other than a compact car. Water cooling mainly includes closed and open type. The open cooling control is mainly performed by people. If the brake is not cooled in time when braking, it will cause quenching. However, closed cooling has a high economic cost, complicated process, and it is difficult to mass-produce these cooling methods. There are four scenarios for coping with the heat decline in below [16].

\subsubsection{Improved Brake Structure and Friction Materials}

Different materials in the high-temperature environment will produce decomposition or even dissolution of the phenomenon, this change in both physical changes and chemical changes, which affect the braking performance is mainly 
the reduction of friction coefficient, so for the friction of the brake material, the higher the thermal stability [17], brake braking performance of the more secure, the better the resistance to thermal decay.

\subsubsection{Air Pressure Shower Cooling}

Air conditioning cooling water system mainly by high-pressure pump to improve the storage tank, through the solenoid valve control water, adjacent water tanks are set in the pressure control valve and the top of the pressure valve. According to the pressure value set before the pressure regulating valve, compressed air through the top of the water tank pressure, the driver relies on the brake pedal or control the water in the cab of the sprinkler switch, the water in the tank spray to the surface of the brake drum to achieve cooling effect, to ensure that the brake temperature is not too high, fully protect the necessary vehicle braking power. In order to solve the braking performance heat decline is mainly the use of water time delay control, equipment simple, easy to modify. But the equipment has some problems: cannot confirm whether there is water in the pool, no layer of compressed air through the sprinkler pipe directly leaking into the air, so that the brake system supply pressure is insufficient, resulting in the car's braking force is not enough even control.

\subsubsection{Forced Wind Cooling}

The cooling system structure is in the existing brake drum structure on the external surface of the joint radial distribution of uniform spread of air-cooled fins, in addition to the bottom of the plate should be installed annular jet nozzle, nozzle to the wind-cooled fin. However, there are some problems that need to be addressed in this device: when the car does not need the brakes to work without the heat dissipation, but the driving also drives the air compressor running together, resulting in a waste of power, a large number of internal energy produced to make the drive shaft speed down, it will cause the cooling effect of incoherent cannot produce ideal cooling effect.

\subsubsection{Water Pump Sprinkler System for DC Motor}

The device has a pipe-connected port to filter water in a water tank, and then a direct current-driven pump produces a constant pressure of filtered water. Using water pressure to control the flow of the valve group, respectively, according to the driver's intention to cool part of the transport, reduce its temperature, the alarm will remind the cold water level below the warning water level, to remind the water shortage of water drivers, in order to ensure traffic safety, the device has a low degree of automation of the defect, cannot adjust the leaching effluent.

\section{Design of Forced Ventilation Cooling System for Drum Brake}

\subsection{System Design Overview}

Based on the previous research results, this paper deepens the analysis and research of brake structure and heat-producing mechanism. The automatic control 
cooling system is developed. This system obtains the pedal work condition, controls the semiconductor refrigeration, uses the electric motor to form the Low-temperature air circulation, the cold air through the brake drum outer wall's air-cooled fin carries away the heat, thus reduces the entire brake the temperature. In the system, the independent variable is the temperature of the brake, each part of the system adjusts its working condition according to the change of the independent variable, thus achieves the most suitable refrigeration effect.

\subsection{Content and Technical Requirements of the Study}

The cooling system uses a semiconductor circuit as an air conditioner to supply cold air. The amount of cooling is controlled by controlling the current of the cooling circuit. The operation of the entire system is controlled by the operation of the brake pedal.

1) General design of system design;

2) Circuit laying;

3) The choice of motor;

4) brake control design;

5) Maintenance and repair inspection.

\subsection{Advantages and Disadvantages of Air Cooling}

The wind cooling is cooled by the heat flux of the cold air. Cooling air flows through the heatsink, which can turn the heat cooling effect.

Air cooling has the following advantages:

1) Water is not used as cooling medium. Reduced maintenance costs, because there is no need to carry out frequency cleaning cooler produced by the scale. The cost of the integration of microbial scaling and things, and so on, simplifies the installation and maintenance process.

2) In the case of loss of power source can still use natural wind energy to complete the cooling work.

3) The air cooling does not have the stress function to the brake, reduces the brake the loss.

Of course, there are some flaws in the cold air, and some design errors and defects should be avoided as far as possible:

1) Air thermal conductivity is lower than water, so the use of air cooling scheme may require higher initial cost.

2) Due to the limitations of the thermal conductivity of the air, the conduction of the same heat to the cost of several times the flow of air, the completion of several times the flow of air will have to rely on the work of high power motors with the job with the resulting is a great work noise.

\section{Design Principle and Overall Scheme of Cooling System}

\subsection{Mechanism Analysis of Thermal Decay of Braking Performance}

Braking, due to friction heat generation cannot quickly dissipate, this will lead to 
a sharp increase in the temperature of the brakes, surface materials decomposition and ablation began, the friction plate temperature rise to a certain value of the brake friction factor drop, according to the friction sheet different manufacturing process differences, In the end, the friction factor will also be different, which affects the main factor of friction factor or temperature change. Friction between the brake pads, the vehicle is mainly converted into the energy of braking friction, in the form of heat consumption of internal energy, on the friction surface sustained heat production. Under the same heat, the temperature field formed by the different thermal properties of the object is very different. The thermal diffusivity of metal friction, heat conduction in the medium, heat affected zone. Organic materials or by friction polymers, the thermal properties of crosses, are easily formed on the collector surface. Drum brake temperature mainly according to the heat balance in the drum, heat from the friction sheet between the surface of the movement, the brake heat mainly depends on radiation cooling and convection cooling, including radiation cooling accounted for the total of $5 \%$ to $10 \%$, convection heat accounted for the total of $80 \%$, The braking part, the accumulation of the brake drum and the remaining part of the friction plate can be produced by various ways, and the temperature will continue to rise.

\subsection{Quantitative Analysis of Cooling System Heat Dissipation}

Nowadays, most automobile brake drums adopt cast iron H 1200 or HT 250 as raw materials, different iron and carbon components of cast iron are different, and change roughly in a certain temperature. According to the principle of additive and sex of heat capacity, it is feasible to analyze three kinds of cast iron by HT 250 thermal melt. Compared with the thermal capacity of manganese steel, the heat capacity is smaller at $400^{\circ} \mathrm{C}$. But the temperature of the brake drum during the working period has been fluctuating, but must be controlled between the bersing.

For the convenience of visual expression, the data in Table 1 is processed by the software (OriginPro 9.0) into a line graph with the temperature as the abscissa and the friction coefficient as the ordinate (Figure 2).

Due to the material properties of the friction material itself, the coefficient of friction changes with temperature. The friction coefficient has a great influence on the braking performance. The main cause of thermal degradation is that

Table 1. Friction coefficient changes with the temperature.

\begin{tabular}{cc}
\hline Temperature $\left({ }^{\circ} \mathrm{C}\right)$ & Friction coefficient \\
\hline 20 & 0.34 \\
100 & 0.35 \\
200 & 0.34 \\
300 & 0.30 \\
400 & 0.23 \\
\hline
\end{tabular}




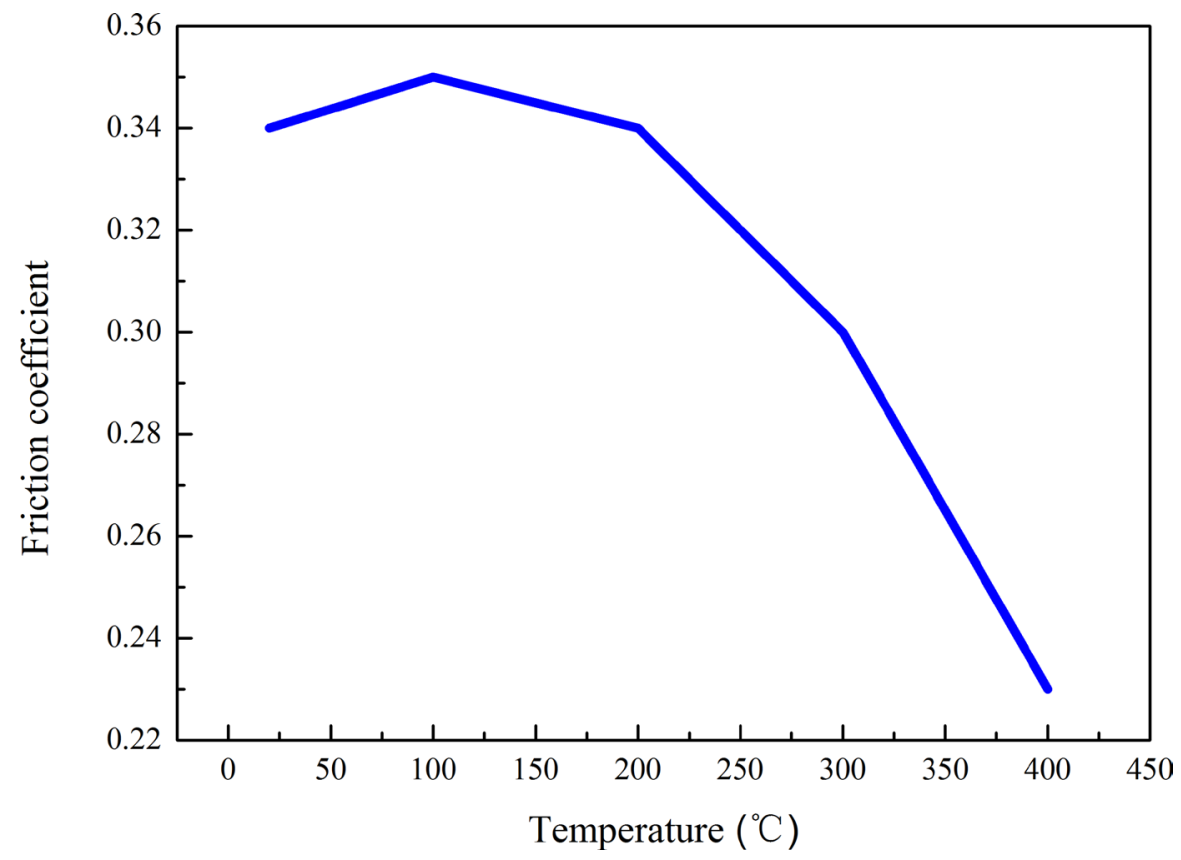

Figure 2. Friction coefficient changes with the temperature.

when the temperature is high, the friction coefficient value will drop to a very small value.

\section{Cooling System Design Parameters}

\subsection{Motor Selection}

Due to the difference in the working environment, the choice of the motor structural form also needs to be matched.

1) According to the actual working environment of the car with too much dust, so the system should use closed-end structure of the motor;

2) In the hot and humid area or relatively humid place, damp heat type motor should be selected;

3) The working environment of the motor has high temperature characteristics. Therefore, the motor that meets the insulation conditions should be selected to ensure good ventilation and heat dissipation conditions when the motor is working.

The speed of the motor should meet the requirements of mechanical transmission. According to the brake temperature rise analysis and cooling requirements, the motor speed needs to reach $1000 \mathrm{r} / \mathrm{min}$.

Select motor capacity:

The motor capacity shows its resistance to load. You can choose a relatively high capacity, so that the motor's resistance to overload will be better.

According to the above conditions, and meet the automotive brake cooling system, the motor voltage is provided by the battery, voltage rating $12 \mathrm{~V} \rightarrow 14 \mathrm{~V}$, select built-in $12 \mathrm{~V} \rightarrow 14 \mathrm{~V}$ built-in small motor, power selection $20 \mathrm{~W}$. We use the 42BYGH401 DC motor. 


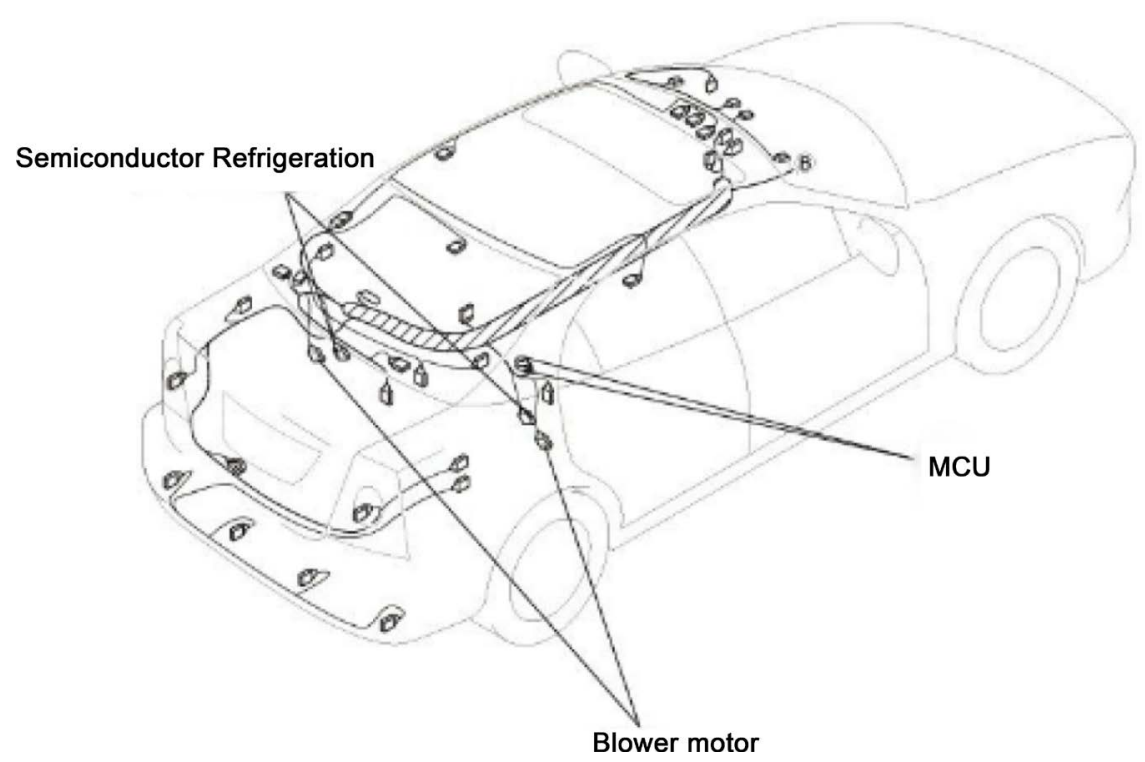

Figure 3. Illustration of automobile brake cooling system.

\subsection{Selection of Semiconductor Cooling Sheet}

Since the driving conditions of the automobile are in the wild driving conditions, the outdoor temperature conditions are relatively extreme, and the low temperature may reach zero. However, condensation occurs when the temperature difference between the temperature and the outdoor temperature is higher than eight degrees Celsius. Therefore, the insulation work is imperative. We choose the TBC1127012 model of semiconductor cooling sheet, which has a maximum current of $12 \mathrm{~A}$, a maximum voltage of $15.4 \mathrm{~V}$, and a cooling power of 106.7 KW, which fully meets the thermal requirements of the brake.

\subsection{Temperature Sensor Selection}

This system uses TS 118 thermopile infrared sensor. It non-contact detection of infrared energy emitted by the object and converts it into a corresponding voltage signal output. It also has less thermal inertia and accurate measurement. Illustration of automobile brake cooling system is shown in Figure 3.

\section{Conclusion}

The brake automatic cooling device adopts low cost, stable and reliable single-chip microcomputer system to implement control, adopts a thermocouple temperature sensor to acquire the temperature change of the brake, and the system has reliable stability. The use of this device to cool the brake can reduce the temperature at any time, thus ensuring the braking performance of the brake. The threshold of cooling and cooling of the system can be determined by the actual vehicle. The fact that the high temperature of the drum brake cannot cool down in time is an important issue affecting the active safety of the vehicle. The device has a positive effect on solving the above problems and has economic and practical value. 


\section{References}

[1] Kwangjin, L. (2000) Frictionally Excited Thermoplastic Instability in Automotive Drum Brakes. ASME, 122, 849-855.

[2] Jiarui, C. (2004) Automotive Construction. China Communications Press, Beijing, 196-216.

[3] Li, W.X. (2004) Structural Analysis and Design Calculation of Automobile Braking System. Tsinghua University Press, Beijing, 7-36.

[4] Blok, H. (1939) Delay Analysis Method for Determining the Seizure Protection of EP Lubricants. SAE Journal, 44, 193-196.

[5] Anderson, A. and Knapp, R. (1990) Hot Spotting in Automotive Friction Systems. Wear, 135, 319-337. https://doi.org/10.1016/0043-1648(90)90034-8

[6] Kong, H.S. and Ashby, M.F. (1990) Fricition-Heating Maps and Their Application. Wear, 135, 319-337.

[7] Barber, J.R. (1967) The Influence of Thermal Expansion on the Friction and Wear Process. Wear, 10, 155-159. https://doi.org/10.1016/0043-1648(67)90087-7

[8] Kennedy, F.E. and Ling, F.F. (1974) A Thermoelastic, and Wear Simulation of a High Energy Sliding Contact Problem. ASME Journal of Lubrication Technology, 96, 497-507. https://doi.org/10.1115/1.3452024

[9] Kollun, D.K., Bodin, X., Desplanques, Y., et al. (2010) Effect of Natural Graphite Particle Size in Friction Materials on Thermal Localization Phenomenon during Stop-Braking. Wear, 268, 1472-1482. https://doi.org/10.1016/j.wear.2010.02.024

[10] Naji, M. and Al-Nimr, M. (2001) Dynamic Thermal Behavior of a Brake System. International Communication in Heat \& Mass Transfer, 28, 835-845.

[11] Masashi, D., Hidetoshi, K. and Khairul, F. (1997) Thermoelasto-Plastic Stress and Thermal Distortions in a Brake Drum. Journal of Thermal Stress, 20, 345-361. https://doi.org/10.1080/01495739708956106

[12] Jacobssen, H. (1999) Analysis of Brake Judder by Using of a Multitude Functions. SAE Paper No. 1999-01-1779.

[13] Segal, L. (1998) Dianostic Method for Vehicle Brakes Quality Assurance and Reliablity. Tchnoion, Israel Institute of Technology, Haifa 32000, Israel.

[14] Daniel, T. (2006) Influence of Materials Properties on Sliding Contact Braking Applications. SAE Paper No. 2006-01-3558.

[15] Apte, A.A. and Ravi, H. (2006) Prediction of Thermal Perform and Stresses in a Disc Brake System. SAE Paper No. 2006-01-3558.

[16] Gao, C., Huang, J., Lin, X., et al. (2007) Stress Analysis of Thermal Fatigue Fracture of Brake Disk Based on Thermo mechanical Coupling. Journal for Tribology, 129, 535-543. https://doi.org/10.1115/1.2736437

[17] Aleksander, Y. and Michal, K. (2010) Temperature and Thermal Stresses in a Pad/Disc during Braking. Applied Thermal Engineering, 30, 354-359.

https://doi.org/10.1016/j.applthermaleng.2009.09.015 